\title{
LA PROTESTA MAPUCHE MÁS ALLÁ (Y MÁS ACÁ) DEL ESTALLIDO SOCIAL ${ }^{43}$
}

\author{
Nicolás Rojas Pedemonte ${ }^{44}$ \\ Diego Gálvez ${ }^{45}$
}

\section{Introducción}

El Estallido Social de octubre de 2019 es un hito histórico, pero no un hecho aislado ni fortuito. Es resultado, en parte, de una crisis institucional, pero también de una acumulación de fuerza movimentista, de nuevas coaliciones de organizaciones y actores, de discursos reivindicativos que el tiempo consolida y aquilata y de la profundización y generalización de la violencia estructural y policial en manos del Estado. El Estallido es resultado de una profunda crisis estructural, pero no se trata de la crisis misma ni se reduce a ésta, pues también y directamente es producto de un conflicto dinámico entre políticas y resistencias encarnadas y desplegadas por actores concretos, por las autoridades y las élites, de un lado y la sociedad civil, del otro. No se trata de un proceso político inexorable, ni menos de un resultado predecible mecánicamente, sobre todo, porque sus costos humanos eran evitables políticamente y respondieron principalmente a los costos que los actores y sobre todo las autoridades estuvieron dispuestas a asumir. Como describimos en nuestro capítulo del libro anterior (Rojas Pedemonte y Gálvez, 2020), el Estallido tuvo su sinopsis en el ciclo de protestas del 2018 en repudio al asesinato de Camilo Catrillanca.

El ciclo de protestas desatado desde octubre de 2019 conjugó diversos discursos y causas, no obstante, destaca la conjunción desde los primeros días de cuatro movimientos urbanos que en noviembre de 2018 ya se habían manifestado en las calles: el movimiento ambientalista contra las zonas de sacrificio; las organizaciones mapuche de Santiago; los estudiantes secundarios; y el movimiento feminista.

45 Universidad Alberto Hurtado dgalvez.pino@gmail.com 
La represión policial desatada en las movilizaciones nacionales en rechazo al asesinato de Catrillanca y contra las zonas de sacrificio, así como el nivel de disrupción alcanzado en esos días de noviembre del 2018 en una capital con microbuses incendiados, más que un teaser referencial de una película aún no rodada, nos mostró un Trailer con gran parte de los actores que veríamos en la película del año siguiente. Es el caso de la ACES y su compromiso asumido en las protestas por Camilo Catrillanca, donde incluso su aún desconocido vocero, Víctor Chanfreau, fue detenido mientras protestaba a la par de organizaciones mapuche urbanas y medioambientalistas ${ }^{46}$. Tampoco se puede desestimar la capacidad política y organizativa que recobró el movimiento feminista desde el 2018, ni la escalada represiva que se evidenció en las últimas marchas "mapurbes" del 12 de octubre en Santiago, destacando particularmente la que ocurrió seis días antes del Estallido Social, con 40 detenidos registrados 47 . Con todo este entramado de organizaciones y articulación progresiva de causas en los últimos años, no sorprende que la wenufoye flameara nuevamente en Plaza Italia, ahora la Plaza de la Dignidad. Menos aún, cuando los primeros en portar la bandera fueron mapuche, incluido Mauricio Lepin Aniñir, nacido en Galvarino, quien la empuñó en la foto histórica del Estallido, en lo más alto del monumento de Baquedano.

Ciertamente, el Estallido alcanzó escala nacional, no obstante, se trata principalmente de una protesta urbana, desatada desde la ciudad de Santiago que resuena y se propaga en el resto del territorio. A diferencia de otros movimientos con raíz campesina y/o indígena, que nacen desde el mundo rural, este ciclo de protestas iniciado en octubre de 2019, se despliega como una movilización en las ciudades y desde las ciudades. En ese sentido, este artículo, más que estudiar la dimensión mapuche del Estallido, estudiará en general la protesta mapuche durante el 2019 y evaluará, en particular, la expresión y el alcance de este proceso histórico de movilización urbana en el territorio mapuche. En especial, se prestará atención a las dinámicas propias de la capacidad movimentista que el movimiento mapuche ha acumulado históricamente en las zonas rurales, frente a la escalada de la protesta urbana que registró el Estallido. Sin entenderlas como realidades contrapuestas o desvinculadas, el presente estudio analizará la protesta mapuche, reconociendo posibles articulaciones entre las diversas geografías, pero también dinámicas que pueden ser propias y particulares.

https://www.eldesconcierto.cl/2018/11/23/estudiante-secundario-de-la-aces-fue-detenido-por-carabineros-y-paso- cuatro-horasinubicable/

47 https://interferencia.cl/articulos/belen-curamil-no-hay-nada-que-celebrar-en-esta-fecha https://www.latercera.com/ nacional/noticia/marcha-encuentro-dos-dos-mundos-deja-saldo-40-detenidos/858965/ 
Así, este estudio pondrá atención en aquellos hechos noticiosos de protesta que se han registrado en el Wallmapu -en particular, en las provincias de Arauco, Malleco y Cautín - durante el año 2019. Se describirán y analizarán, en base a las noticias cubiertas por distintos periódicos en línea y habida cuenta de los sesgos que conlleva el tratamiento mediático del conflicto (Amolef, 2005; Labrín, 2011), repertorios de protesta que incluyen, desde aquellos convencionales-pacíficos hasta los más confrontacionales y de marcada violencia política. Con el objetivo de alcanzar una mayor diversidad ideológica y más amplia cobertura en los territorios, este artículo ha incluido tanto a los grandes medios de prensa o vinculados a medios corporativos como El Mercurio, Soy Chile, La Tercera y Biobío, como también a aquellos medios independientes o locales que permitieran aportar con otra perspectiva y cobertura del conflicto - más crítica o, en algunos casos, afín al movimiento- como Mapuexpress, El Ciudadano, Diario UChile y El Werken.

La búsqueda de hechos noticiosos se realizó a través de cada página web de los medios de prensa en línea, principalmente, recurriendo a las herramientas de Google en aquellos casos donde no fuera posible realizar la búsqueda de manera óptima. Los filtros aplicados para llegar a cada protesta en territorio mapuche se realizaron según fecha de publicación de la noticia y palabras claves, como "mapuche”, "Arauco", Cautín", "Malleco" y sus respectivas comunas. La búsqueda fue seguida de una sistematización de cada hecho noticioso, construyendo una base de datos en la que se incluyeron variables como "Región", "Provincia”, "Comuna", "Fecha de Publicación", "Fuente de información”, “Coordenadas Geográficas”, “Tipo de repertorio” y "Tipo de conflicto", entre otros.

\section{Hechos de protesta en un territorio históricamente en conflicto}

Los repertorios de protesta durante el 2019, tal como expone el Gráfico 1, dan cuenta de un conflicto que se concentró mayoritariamente en el ámbito forestal y en la judicialización de la contienda. Por un lado, $19 \%$ de las acciones corresponden a sabotajes a la industria maderera, en lo que el gráfico categoriza como "daño a maquinaria" y que aumentó tres puntos porcentuales frente al año anterior. Esta tendencia se condice con el estudio de Maher, Rojas Pedemonte y Gálvez (aún inédito), que identifica una sostenida escalada de la protesta antiforestal desde el año 2014 a la fecha. Por otro lado, las acciones legales o judiciales también concentraron 19\% de los eventos. Sin duda, como bien lo expone el capítulo de CIDSUR en este libro, corresponde a lo que ellos denominan la "judicialización de la protesta social", con particular énfasis desde el Estallido Social de octubre. Si bien, como demuestra aquel capítulo, la mayor parte de la judicialización de la protesta durante el periodo se vinculó a "judicialización represiva”, aquel 19\% correspondería, específicamente, a acciones de denuncia y protección de los derechos humanos frente a la generalización de los atropellos y violaciones a los derechos humanos documentados por cinco informes internacionales desde octubre. 


\section{Gráfico 1: Total de hechos noticiosos en las tres provincias de estudio}

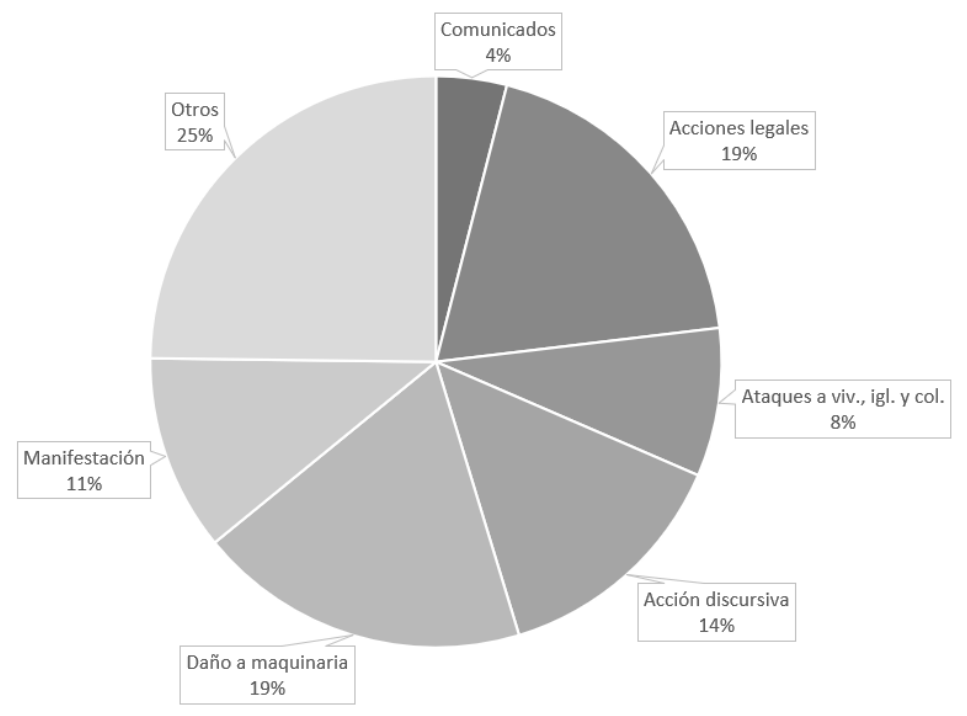

Fuente: Elaboración propia según medios de prensa estudiados

A la cotidiana vulneración de derechos de las comunidades y organizaciones mapuche durante el Estado de Excepción, se sumó una política generalizada de castigo y represión a la protesta social, que redundó también en mayor represión a miembros del Pueblo Mapuche y en el consecuente incremento de denuncias judiciales. El conflicto y la represión son procesos interactivos y los activistas mapuche tampoco se quedaron de brazos cruzados. La represión consiste, básicamente, en el aumento de los costos multidimensionales de la protesta y la persecución de un fin en sí mismo: la desmovilización (Tilly, 1978). No obstante, como se evidencia en las últimas dos décadas en Wallmapu, la represión ha tenido un efecto radicalizador, más que desmovilizador (Pairican, 2014; Rojas Pedemonte y Miranda, 2016; Rojas Pedemonte y Gálvez, 2020), y durante el 2019, mientras el Estado más reprimió, el movimiento mapuche más radical fue contra las empresas madereras y más activo se hizo en el ejercicio de la denuncia ${ }^{48}$. 
Con todo, esa radicalización estuvo lejos de ser dispersa y "anti todo", pues, durante el 2019, se enfocó más aún en la resistencia al extractivismo y mucho menos en los ataques a vivienda, iglesias o colegios. Estas últimas acciones no superaron el 8\% de los repertorios estudiados, bajando cinco puntos porcentuales en relación al 2018. Ciertamente, el carácter histórico y estructural del conflicto consolida determinados repertorios de protesta y los objetivos de las acciones políticas que despliega el movimiento. No obstante, llama particularmente la atención el significativo aumento porcentual de las acciones contra las empresas forestales en la Provincia de Arauco, como lo evidencia el Gráfico 2, aumentando en $75 \%$ el porcentaje de sabotajes a maquinarias forestales frente a las cifras del año 2018, pasando de concentrar 20\% de los repertorios en aquel año, a 35\% durante el 2019. En general, se mantuvieron en niveles similares al año anterior el resto de las modalidades más violentas y disruptivas de protesta: ataques a vivienda (20\%) y emboscada (9\%). Sin embargo, el agregado de acciones más disruptivas, sumando el sabotaje a maquinarias, concentra el 64\% de las acciones, superando en $16 \%$ al año anterior, evidentemente explicado por el aumento de las acciones contra las empresas madereras.

\section{Gráfico 2: Hechos noticiosos según repertorio de protesta, Provincia de Arauco}

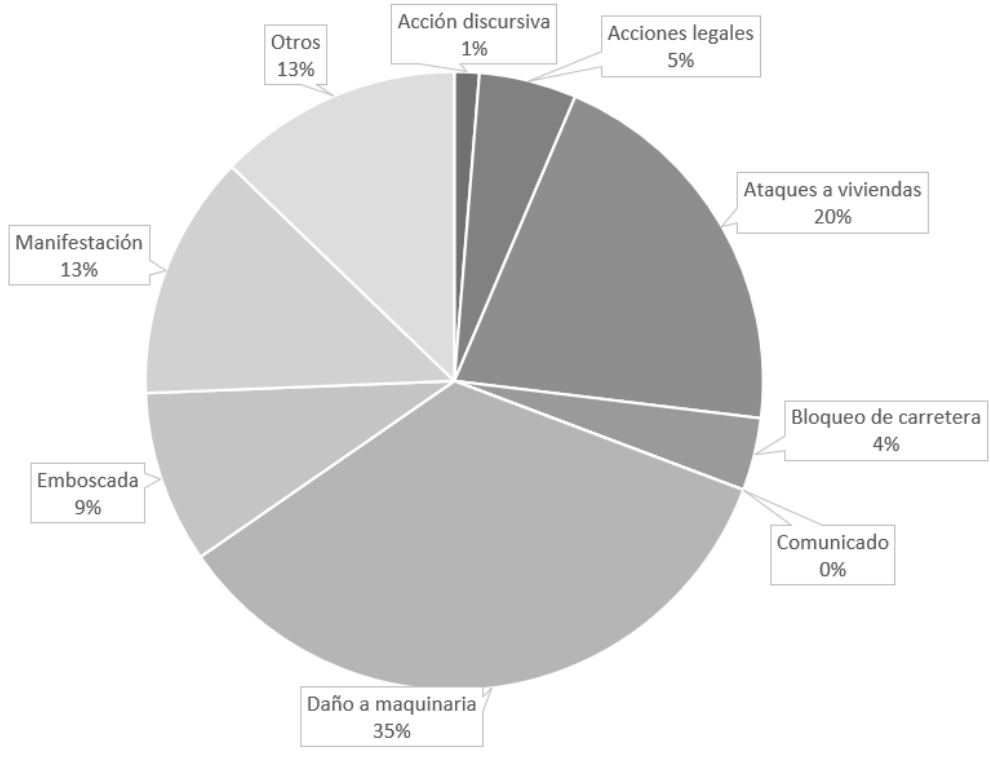

Fuente: Elaboración propia según medios de prensa estudiados 
Por su parte, la Provincia de Malleco, aquella que fue golpeada el año anterior por el asesinato de Camilo Catrillanca en Temucuicui, disminuyó porcentualmente la protesta altamente disruptiva durante el 2019, como evidencia el Gráfico 3. Mientras en el año 2018 este tipo de repertorios concentró 35\% de las acciones, durante el 2019 disminuyó tres puntos porcentuales, registrando 32 de los eventos de protesta. Complementariamente, fueron las acciones legales relacionadas con las denuncias de violaciones a derechos humanos, la que concentraron la mayor parte de las acciones reivindicativas de la causa mapuche. Durante el 2019, las acciones judiciales representaron $22 \%$ de los repertorios de acción colectiva del movimiento mapuche, es decir, ocho puntos porcentuales más que en el año anterior. Por cierto, los "coletazos" del caso Catrillanca y la represión acumulada en la provincia, explicarían en gran parte esta tendencia a la judicialización del conflicto. En efecto, al estudiar las modalidades de supresión de la protesta que desarrolla el Estado, se identifica que esta provincia concentró, durante el 2019, la mayor parte de las acciones de supresión de la protesta en todo el territorio mapuche estudiado, acumulando 43,4\% de las acciones. En particular, fueron mayoritariamente acciones de represión policial, acumulando este territorio el 60,6\% de las acciones de las fuerzas de orden contra el Pueblo Mapuche. Esta dinámica reitera un patrón evidenciado ya en el primer Gobierno de Piñera, donde el "espectáculo represivo" (Rojas Pedemonte y Miranda, 2016) se concentró en Malleco contra las comunidades autónomas y, en gran medida, contra la Alianza Territorial Mapuche (ATM).

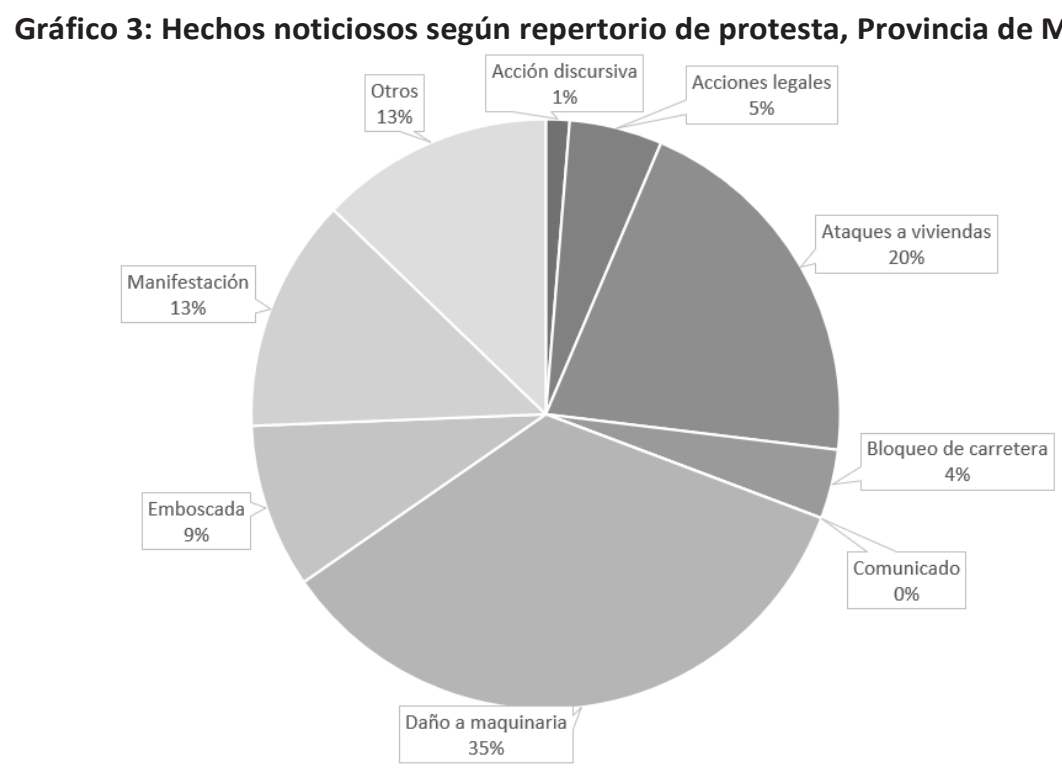

Fuente: Elaboración propia según medios de prensa estudiados 
La provincia de Cautín, que incluye la capital regional de La Araucanía, Temuco, es aquella que concentra la mayor cantidad de protesta total del territorio estudiado (41\%), similar a la cifra del año 2018. Como lo expone el Gráfico 4, esta provincia — al igual que el año anteriores la que registra el mayor porcentaje de repertorios de baja disrupción. Destaca aquí un significativo aumento de las acciones reivindicativas de corte legal, superando en 28 puntos porcentuales al año 2018. Ciertamente, la concentración de oficinas públicas y agencias del sistema judicial en la capital regional propicia una tendencia a la contienda institucional-legal en la provincia, no obstante, el aumento significativo de la judicialización protectora da cuenta, en gran medida, del recrudecimiento de la represión durante el 2019 y, en particular, en las semanas posteriores al 18 de octubre. Esto coincide, además, con las estadísticas que sitúan a esta provincia como aquella que más acciones de supresión judicial de la protesta concentra en el territorio estudiado (61\%). Es decir, esta provincia se posiciona, y especialmente la comuna de Temuco, como epicentro de la judicialización del conflicto. En consonancia con ello, destaca esta como aquella que concentra la mayor cantidad de acciones políticas de supresión de la protesta, 5 de las escasas 12 respuestas institucionales de "política indígena" a las demandas mapuche en todo el territorio estudiado.

Como se evidenció en el volumen del año 2018 (Rojas Pedemonte y Gálvez, 2020), las particularidades históricas de la estructura social y productiva de esta provincia, con un marcado clivaje colonial y una matriz agrícola ganadera, definen un territorio donde la lucha antiforestal no monopoliza la conflictividad, como sí ocurre en Malleco y, sobre todo, en Arauco. De cualquier modo, es significativo también el porcentaje de sabotajes y daños a maquinaria (15\%), versus la baja concentración de repertorios asociados a los atentados a iglesias, en la provincia que inauguró y concentró estas prácticas. Esto podría vincularse - en cierta medida- con el giro discursivo de la organización local, Weichan Auca Mapu (WAM), que luego de tener un énfasis antioccidental, optó por enfocarse - en sus comunicados - en la lucha contra el gran capital como la mayor parte de las organizaciones insurreccionales, entre ellas la histórica Coordinadora Arauco-Malleco (CAM). 


\section{Gráfico 4: Hechos noticiosos según repertorio de protesta, Provincia de Cautín}

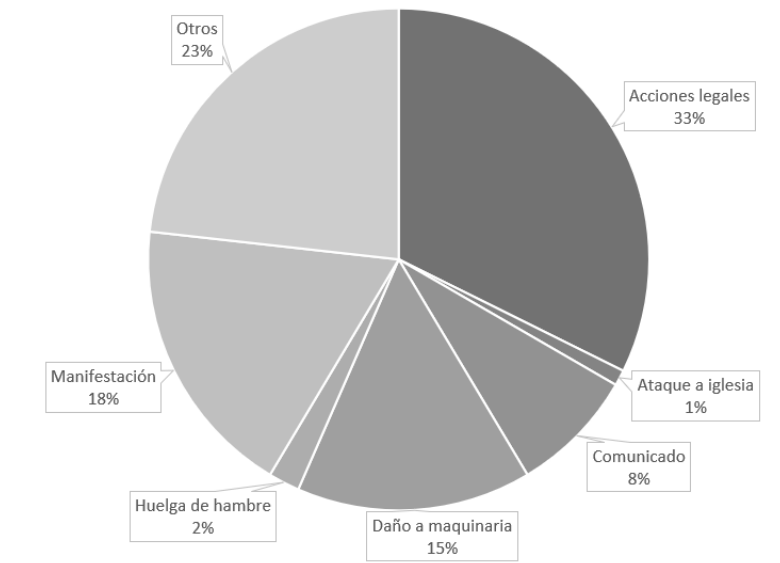

Fuente: Elaboración propia según medios de prensa estudiados

\section{Territorialización del conflicto, la protesta en el espacio}

En el estudio desarrollado para el volumen anterior que abordó la protesta del año 2018, describimos tres realidades territoriales asociadas a determinadas matrices productivas y actores sociales específicos vinculados a patrones y dinámicas de contienda particulares. Estas tres geografías del conflicto se asocian a los tres principales focos de protesta, una en cada provincia estudiada. Estos tres epicentros también destacan en la distribución territorial de la protesta durante el año 2019, como muestra la Figura 1, y se consolidan en las últimas dos décadas como realidad interconectadas, pero con ciertas pautas propias. Grosso modo, la primera realidad socioterritorial del conflicto corresponde a la del mundo lafkenche de la Provincia de Arauco, entre Tirúa y Cañete. Como se describió en la sección anterior sobre los repertorios de protesta, se trata de un conflicto principalmente en torno al extractivismo forestal y caracterizado por repertorios altamente disruptivos de sabotaje a las empresas madereras. La segunda realidad territorial es parte de la Provincia de Malleco, con Collipulli y Ercilla como las comunas con mayor concentración de la protesta. Ercilla es la comuna que ha concentrado gran parte de los esfuerzos desmovilizadores/represivos del Estado en los últimos dos años.

Como se describió en la sección anterior, es esta realidad territorial del conflicto la que, por un lado, concentra la mayor parte de la represión policial y, por otro, presenta la mayor diversidad y versatilidad de los repertorios de protesta, donde se despliegan acciones altamente disruptivas, pero también y, sobre todo, acciones judiciales que hacen frente a La nueva arremetida represiva 
desplegada por el Gobierno de Piñera desde el año 2018. La complejidad de esta geografía del conflicto aumenta cuando se conjuga la presencia del extractivismo forestal con la gran propiedad de particulares, a diferencia de Arauco, donde la matriz es principalmente extractiva. Por último, la tercera geografía del conflicto se localiza en Temuco, sus alrededores y conurbaciones, como Padre Las Casas. Se caracteriza por una conflictividad donde el clivaje étnico cultural y los problemas de convivencia destacan, tendiendo a la judicialización. Este territorio se distingue así de aquellos cruzados por el extractivismo, donde la conflictividad gira principalmente en torno a la presencia forestal y a la canalización policial y violenta.

Figura 1: Focos de protesta, territorio de estudio

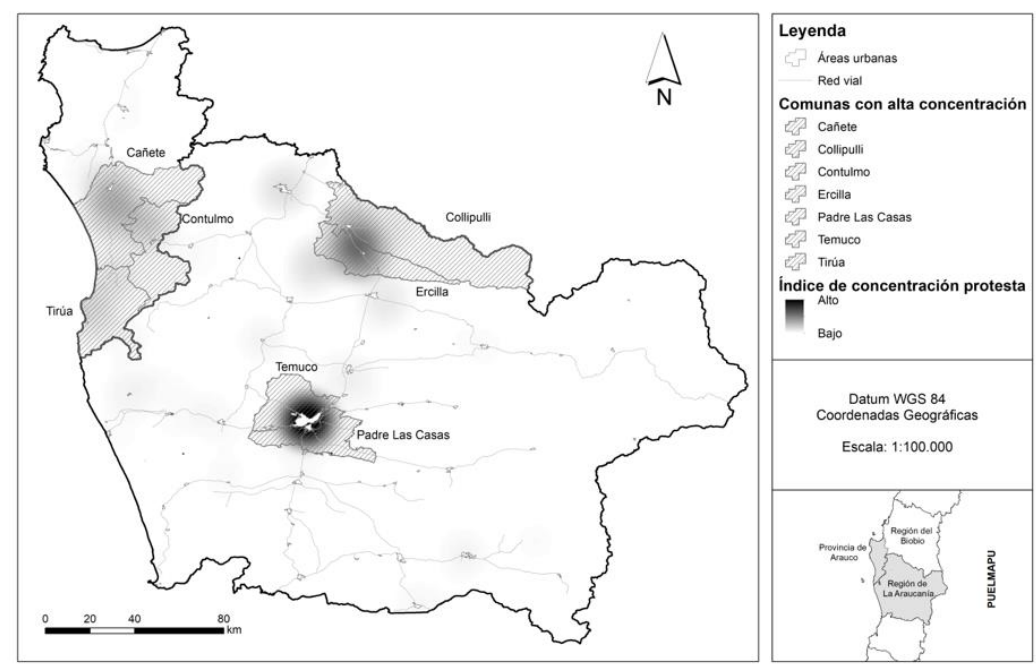

Fuente: Elaboración propia según medios de prensa estudiados

Si bien esta descripción no agota la dinámica de estas realidades y desestima los aspectos comunes, permite reconocer tendencias y pautas locales que le imprimen características locales ineludibles al conflicto. Finalmente, vale destacar que la concentración de inusuales iniciativas de canalización políticas del conflicto en la Provincia de Cautín, da cuenta de un territorio marcado por las pautas de la gran capital económica y política de La Araucanía, Temuco. Así mismo, también describe un epicentro del conflicto en torno a una realidad urbana que fue más alterada por el Estallido que la realidad rural de Tirúa o Ercilla. Un territorio urbano que incrementó su actividad movimentista, pero que también padeció altos niveles de descontrol represivo por parte de las fuerzas de orden desde el mes de octubre. 
A diferencia de la distribución territorial de la protesta durante el 2018, el Estallido de 2019 concentró la conflictividad en la gran capital de La Araucanía. El año anterior, la movilización mapuche mostró una alta concentración en los tres focos provinciales, sin embargo, el mapa de la Figura 1 insinúa que el Estallido Social fue más un fenómeno urbano que rural. Comunidades de zonas rurales se trasladaron masivamente a históricas manifestaciones en las principales ciudades de Wallmapu, sin embargo, no se tradujo en una participación cotidiana por parte de ellas durante los meses del Estallido. Las organizaciones y comunidades en resistencia territorial no vieron alteradas sus rutinas de lucha durante el Estallido, aun cuando sí estuvieron mayormente expuestas a la arremetida represiva propia del Estado de Excepción, principalmente allí donde se desarrollan faenan forestales. La resistencia territorial mapuche en las comunidades rurales es un proyecto político e histórico de larga data que, si bien no es ajeno al contexto nacional, guarda cierta independencia local. A pesar de que el Estallido aumenta la cantidad de movilizaciones en el territorio a fines del 2019 y emergen hitos relevantes como la 'desmonumentalización', además de abrirse oportunidades políticas y asociativas para la causa mapuche, no es claro aún que la movilización desatada en las ciudades represente un antes y un después para el movimiento autonomista local.

El conflicto en territorio mapuche es estructural y presenta una escalada sostenida en la última década, con actores y proyectos políticos definidos. La reconfiguración del escenario y de las fuerzas políticas a nivel nacional podría ser interpretada como una oportunidad por parte del movimiento mapuche, sin embargo, la lectura del escenario y de la historia no es un ejercicio precipitado en el pensamiento mapuche. Por ejemplo, entrevistas desarrolladas en Tirúa durante los primeros meses del Estallido, dan cuenta de que la experiencia de resistencia cotidiana y la larga historia aprendida por las comunidades le imprimen mesura a su interpretación del Estallido Social. Se identificó solidaridad con la causa en las visiones y discursos de las comunidades rurales, pero sobre todo cautela frente a la nueva lucha desatada en las urbes y, en particular, acerca del curso que la política y los políticos le darán al proceso.

\section{Dinámicas del conflicto: la protesta mapuche durante el 2019}

La dinámica de la protesta durante el 2019 muestra dos micro ciclos, como lo ilustra el Gráfico 5. El primero, asociado principalmente a la protesta contra el proceso de consulta y el segundo, asociado al Estallido Social. El caso Catrillanca se posicionó como la causa más aludida en las acciones reivindicativas del año. También se evidencia que el Estallido Social se tradujo en una importante alza de la protesta convencional y solo en un leve incremento de las acciones más disruptivas relacionadas a la causa mapuche. Esto refuerza la tesis aquí planteada sobre el carácter principalmente urbano del Estallido y su acotado impacto en las acciones de las organizaciones más disruptivas con un despliegue principalmente rural. Al respecto, es significativo que el ciclo de protesta mayo-julio, asociado al rechazo a la Consulta Indígena, muestra niveles de protesta 
cercanos a los registrados durante el Estallido, tanto en su modalidad convencional como en la más disruptiva. Es decir, esto da cuenta de una permanente actividad movimentista que durante el Estallido vivió un impulso, pero que no fue drástico.

\section{Gráfico 5: Dinámica de la protesta según disrupción y causa aludida (frecuencia mensual)}

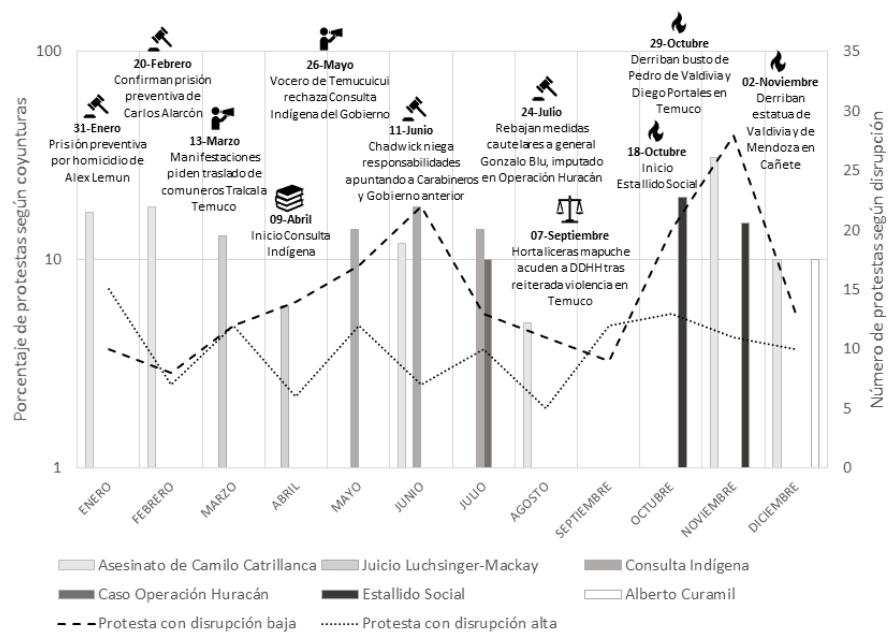

Fuente: Elaboración propia según medios de prensa estudiados

Un análisis semanal del ciclo mayo-julio, a partir del Gráfico 6, permite identificar que la semana del 21 de mayo es aquella con mayor cantidad de protesta mapuche de alta disrupción. La radicalidad de la protesta durante esta semana — como se verá posteriormente en el Gráfico 7es equivalente a la desplegada en la primera semana del Estallido e incluso mayor a la disrupción registrada en la semana del primer aniversario del asesinato de Camilo Catrillanca. Durante esta semana se manifiesta rechazo a la Consulta Indígena y se despliegan acciones de reivindicación territorial, dentro de las cuales un miembro de la comunidad Antonio Calbún de Victoria recibió un disparo de bala en su cabeza ${ }^{49}$, sumándose al ataque reciente que hace pocas semanas había recibido José Queipul en Traiguen a fines de abril ${ }^{50}$.

49 https://www.cooperativa.cl/noticias/pais/pueblos-originarios/mapuche/comunidad-denuncia-que-mapuche-resulto- herido-abala-en-operativo-policial/2019-05-28/154356.html

50 https://www.biobiochile.cl/noticias/nacional/region-de-la-araucania/2019/04/30/comunero-mapuche-resulta-herido- debala-tras-procedimiento-policial-en-ercilla.shtml 
Estos eventos ejemplifican la sistemática represión policial orientada a aquella geografía del conflicto más golpeada desde el 2018, y coincidentemente la más espectacularmente reprimida durante el primer gobierno de Sebastián Piñera (mientras los dos gobiernos de Bachelet orientaron sus mayores esfuerzos desmovilizadores a la Provincia de Arauco en protección de las empresas forestales allí concentradas). Por su parte, el mayor auge de protesta convencional, de menor impacto disruptivo, se registró en la semana del primero de julio, coincidiendo con acciones en contra de la Consulta Indígena.

\section{Gráfico 6: Dinámica de la protesta según disrupción y causa aludida (semanas mayo-julio)}

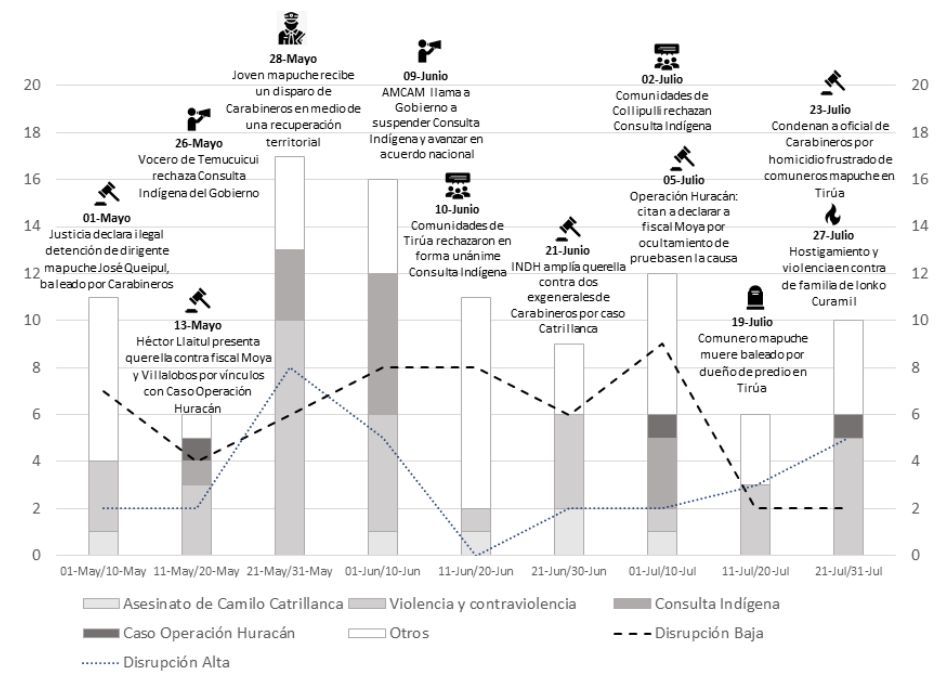

Fuente: Elaboración propia según medios de prensa estudiados

Como se adelantó más arriba, el ciclo del Estallido, en lo que respecta a la protesta mapuche, se desplegó con mayor impacto en la realidad urbana. El Gráfico 7 describe un ciclo de protesta mapuche con dos semanas de apogeo. La primera semana del Estallido es la que concentra la mayor cantidad de acciones disruptivas, mientras que la semana del aniversario del asesinato de Camilo Catrillanca presenta el mayor PEAK de protesta con baja disrupción, es decir, principalmente manifestaciones convencionales y pacíficas. Lo más significativo de este ciclo se expresa en lo que ha sido conocido como "desmonumentalización" o derribamiento de estatuas de íconos coloniales o de las fuerzas armadas chilenas; un repertorio de protesta popularizado por los indígenas zapatistas, quienes el 12 de octubre de 1992, en San Cristóbal de las Casas, precipitaron la figura del conquistador de Chiapas, Diego de Mazariegos. 
Destacó durante el Estallido el derribamiento del busto de Pedro de Valdivia y Diego Portales en Temuco, el 29 de octubre, del busto de Cornelio Saavedra, el 30 de octubre en Collipulli, de la estatua del propio Valdivia y García Hurtado de Mendoza en Cañete, el 2 de noviembre, y de la figura de Arturo Prat en Temuco. Sin duda, se trata de acciones con una fuerte carga simbólica y reivindicativa, en sintonía con el proyecto político decolonial desplegado hace décadas por las principales organizaciones mapuche. No se trata de meras acciones vandálicas o destructivas, sino de iniciativas autoafirmativas, que canalizaron energía transformadora, reforzaron identidades y comunicaron la necesidad de revertir el orden colonial aún vigente. Sin bien la subversión de los íconos coloniales no es algo nuevo en territorio mapuche, y anteriormente se atentó contra estos estatus de íconos coloniales, la desmonumentalización emerge como un nuevo repertorio desde el Estallido e incluso durante el año 2020, ha continuado desplegándose ${ }^{51}$.

\section{7: Dinámica de la protesta según disrupción y causa aludida (semanas octubre-diciembre)}

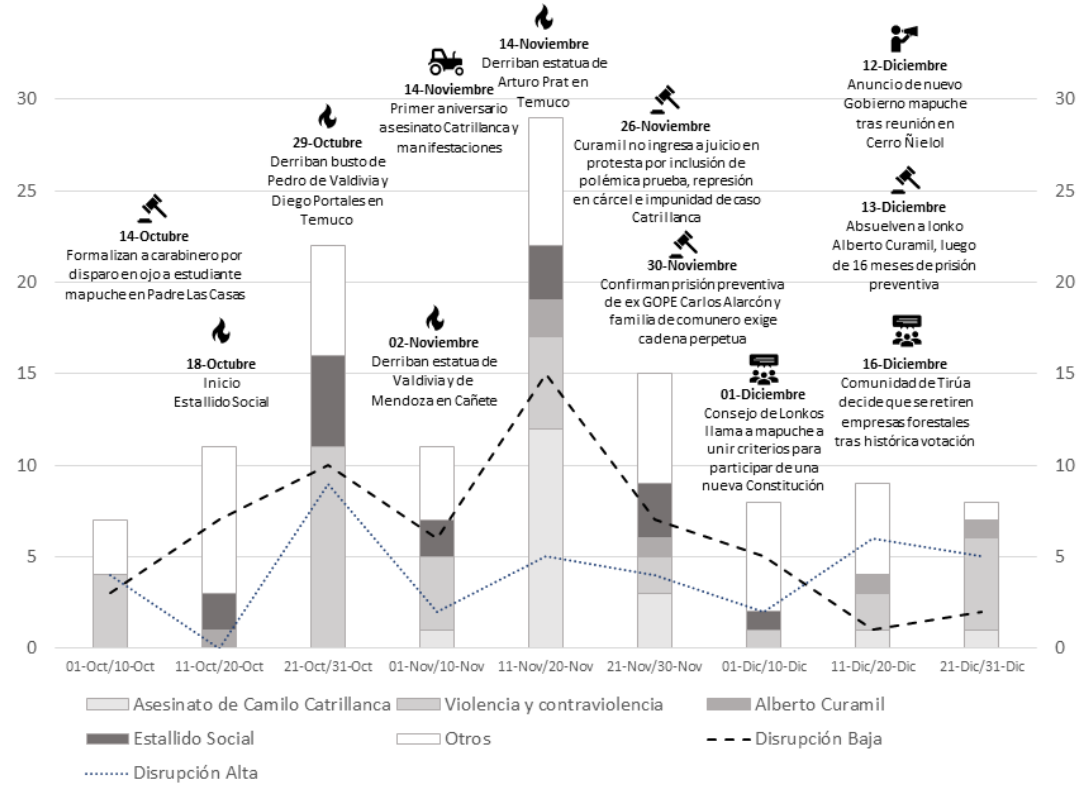

Fuente: Elaboración propia según medios de prensa estudiados 
Estos hitos del Estallido en Wallmapu se desplegaron naturalmente en plazas de ciudades y tuvieron, por tanto, un carácter urbano, no obstante, en ellos confluían diversos actores mapuche y no mapuche, militantes urbanos y también de comunidades rurales. Tal fue el caso, por ejemplo, de las históricas manifestaciones en Cañete donde se congregaron miembros de diversas comunidades y organizaciones lafkenches de la Provincia de Arauco. Diversos actores también confluyeron en el resto de las plazas de ciudades del territorio mapuche.

El ciclo del Estallido, por cierto, continuó durante el verano del 2020, pero en lo que concierne a este estudio, es importante mencionar que el 2019 culminó con cierta radicalización de los repertorios y diversas manifestaciones y comunicados que cuestionaron la canalización política del conflicto social a través del Acuerdo Político por la Paz. Entre estas acciones, destaca el TRAWÜN convocado por el Consejo de Todas La Tierras (CTT) en el Cerro Ñielol el 11 y 12 de diciembre, donde se comunica la decisión - ya conocida en la agenda del CTT- de conformar un Gobierno mapuche. El alcance político de las diversas agendas y las posibilidades de articulación e impacto en la transformación institucional son abordados con mayor detalle en diversos capítulos de este libro ${ }^{52}$. Con todo, es destacable que en diciembre, luego de la institucionalización del conflicto a través del Proceso Constituyente y de la indiscriminada represión de octubre y noviembre documentada en los informes internacionales, disminuyó significativamente la protesta convencional asociada a la movilización urbana del Estallido, mientras las acciones más radicales mantuvieron cierta estabilidad asociada al conflicto estructural y a la capacidad disruptiva propia de las organizaciones mapuche insurreccionales.

Al igual que la desmovilización en Santiago de la Plaza Ñuñoa y de su moderada militancia progresista luego del acuerdo político por la nueva Constitución y de los elevados costos humanos de la represión callejera, gran parte de las manifestaciones en las plazas de las ciudades de Wallmapu disminuyeron su convocatoria y dejaron de concentrar la actividad contenciosa. El conflicto retomó su curso y su histórica distribución territorial, con una sostenida actividad movimentista en las zonas rurales. Si acaso los contenidos de esta lucha, sus agendas y discursos, las alianzas y el contexto político, abren o no paso a un nuevo ciclo de conflicto, solo será posible evaluarlo con la perspectiva del tiempo que dará el estudio de su dinámica en los años venideros. 


\section{Conclusiones}

Este artículo estudió los diferentes repertorios de protesta mapuche durante el año 2019 en las provincias de La Gran Araucanía: Arauco, Cautín y Malleco. Se ha puesto especial atención en las dinámicas que se han desplegado este año, pero también se ha resaltado su desarrollo en comparación con las dinámicas analizadas en el anuario del 2018. Así, los resultados han dado cuenta de un conflicto fuertemente concentrado en la protesta antiforestal y en la judicialización de la contienda como respuesta a los generalizados atropellos y violaciones a los derechos humanos que viven las comunidades mapuche, sobre todo teniendo como antecedente el asesinato de Camilo Catrillanca el año anterior. Por otro lado, en la geografía del conflicto se remarcan tres realidades territoriales en el Wallmapu. La realidad lafkenche de la Provincia de Arauco mostró un conflicto en torno al extractivismo forestal, con repertorios altamente disruptivos de sabotaje a las empresas madereras. Malleco, con especial concentración en Collipulli y Ercilla, mostró una realidad que combina diferentes repertorios de protesta, aumentando las acciones judiciales ante la arremetida represiva del Gobierno de Piñera desde el 2018 en la zona. Finalmente, Cautín destacó, por un lado, por una tendencia hacia la judicialización del conflicto y, por otro, como el mayor de los epicentros estudiados del conflicto, desplegado en torno a una realidad urbana que fue más alterada por el Estallido y que se concentró en la gran capital económica y política de La Araucanía, Temuco.

En este sentido, sin duda la presencia de un hecho histórico en Chile como el Estallido Social de octubre del 2019, condiciona el curso de la contienda política y movimentista de los territorios estudiados. Sin embargo, los resultados aquí expuestos han relevado que, si bien el Estallido influye en un aumento en la cantidad de movilizaciones a fines del 2019 — sobre todo en la protesta convencional-, abriendo oportunidades políticas para la causa mapuche, no queda claro que represente un antes y un después para el movimiento mapuche del territorio. El conflicto en territorio mapuche es estructural y ha presentado una escalada sostenida durante la última década, por lo tanto, se puede sostener que el Estallido es un evento relevante, pero no único para el Pueblo Mapuche. Más bien, pareciera que se configura como un hito histórico para el pueblo chileno y para los militantes mapuche urbanos, pues fueron ellas y ellos quienes protagonizaron aquella movilización social que se concentró en las principales ciudades del país y quienes también, seguramente, ya habían estado protestando el año anterior contra la represión y el asesinato de Camilo Catrillanca.

Al ser el Estallido Social un evento eminentemente urbano, sus protagonistas despliegan ciertos repertorios de protesta como las manifestaciones convencionales en las ciudades, teniendo acotado impacto en las rutinas de aquellas organizaciones más disruptivas que se despliegan principalmente en al ámbito rural hace décadas. Sin embargo, sí es importante resaltar la desmonumentalización como dinámica de la protesta urbana a partir del Estallido, al tratarse de acciones en sintonía con el proyecto decolonial desplegado intensivamente en las últimas décadas 
por las principales organizaciones mapuche. Estos eventos dieron cuenta de una confluencia de actores mapuche y no mapuche, militantes urbanos y también comunidades rurales en las ciudades.

Por otro lado, el Estallido ha evidenciado que la lucha no es de un pueblo contra otro, sino una pugna contra un modelo de desarrollo, donde las solidaridades y alianzas emergen en un horizonte de dignidad común proyectado en el tiempo. Aun cuando las demandas mapuche son por derechos colectivos y territoriales, son también demandas populares por dignidad y el Estallido ha dado cuenta de que su lucha es contra el modelo y no contra el pueblo chileno, el cual emerge más bien como un potencial aliado. Tal como lo expresara Claudio Alvarado Lincopi ${ }^{53}$, el movimiento mapuche es "un movimiento democratizador del país" y procura depositar el poder y la toma de decisiones en quienes habitan los propios territorios.

El Estallido ha visibilizado y también propagado a las ciudades la represión política de la protesta social que cotidianamente se vive en territorio mapuche. Es en última instancia, la ilegitimidad social del modelo chileno la que se procura contrarrestar artificiosamente mediante la represión sistemática de la protesta social, por la vía policial y judicial. De tal manera, urge contar con un nuevo contrato social que sustente legítimamente el orden y la convivencia, pues hoy tanto el Pueblo Mapuche como el pueblo chileno cuentan con presos políticos y víctimas de la represión sistemática desplegada contra la protesta social. En definitiva, es la ilegitimidad de un modelo vacío de autoridad, la que transforma a la violencia y represión en dispositivos de la más alta necesidad política. Finalmente, es necesario apuntar que, si bien el proceso constituyente se configura como potencial camino de paz y legitimidad, también representa una amenaza y riesgo de generar una nueva fractura o una profundización de las desconfianzas si no se considera la efectiva participación política de los pueblos originarios en la construcción de sus derechos fundamentales. Esto es particularmente crítico a la luz de las lamentables experiencias históricas de engaños y promesas no cumplidas del Estado, que no han hecho más que mermar las confianzas y fortalecer la protesta insurreccional como alternativa para la canalización de las demandas políticas del Pueblo Mapuche.

53 https://www.eldesconcierto.cl/2020/08/11/claudio-alvarado-100-dias-de-la-huelga-de-hambre-confianzas-dialogar/ 


\section{Bibliografía}

AMOLEF, F. (2005). La alteridad en el discurso mediático: los mapuche y la prensa chilena. Boletín IFP, 2(6).

LABRÍN, J. M. (2011). Análisis de cobertura y tratamiento de conflictos indígenAs 2010-2011.

Santiago de Chile: Universidad de Chile/Unesco.

PAIRICAN, F. (2014). Malon. La rebelión del movimiento mapuche 1990-2013. Pehuén Editores.

ROJAS PEDEMONTE, N., \& GÁLVEZ, D. (2020). La protesta mapuche como proceso interactivo: Espacios y dinámicas del conflicto en el retorno de Piñera. En N. Rojas Pedemonte, C. Lobos, \& D. Soto, De la operación Huracán al Comando Jungla. Anuario del conflicto en territorio mapuche, 2018 (págs. 16-39). Santiago: Observatori del Conflicte Social. Universitat de Barcelona.

ROJAS PEDEMONTE, N., \& MIRANDA, O. (2016). Dinámica sociopolítica del conflicto y la violencia en territorio mapuche. Particularidades históricas de un nuevo ciclo en las relaciones contenciosas. Revista de Sociología(30), 33-69.

TILLY, C. (1978). From Mobilization to Revolution. McGraw-Hill.

\section{Cronología}

\begin{tabular}{|c|c|c|}
\hline Fecha & $\begin{array}{l}\text { Acontecimie } \\
\text { nto }\end{array}$ & Descripción \\
\hline $\begin{array}{l}24 \text { de } \\
\text { enero } \\
\text { de } \\
2019\end{array}$ & $\begin{array}{l}\text { Condena por } \\
\text { cuatro años a } \\
\text { ex carabinero } \\
\text { en caso } \\
\text { Brandon } \\
\text { Hernández }\end{array}$ & $\begin{array}{l}\text { Condenan a más de cuatro años de libertad } \\
\text { vigilada a ex carabinero que disparó por la espalda } \\
\text { a joven mapuche. El Tribunal Oral de Angol } \\
\text { sentenció a Christian Rivera por los delitos de } \\
\text { lesiones graves y vejación injusta, } \\
\text { respectivamente. }\end{array}$ \\
\hline $\begin{array}{l}20 \text { de } \\
\text { febrer } \\
\text { o } \\
\text { de } \\
2019\end{array}$ & $\begin{array}{l}\text { Confirman } \\
\text { prisión } \\
\text { preventiva de } \\
\text { Carlos } \\
\text { Alarcón }\end{array}$ & $\begin{array}{l}\text { Caso Catrillanca: Corte de Temuco confirma } \\
\text { prisión preventiva de Carlos Alarcón. El } \\
\text { exuniformado se encuentra imputado como autor } \\
\text { del delito consumado de homicidio del comunero } \\
\text { mapuche. }\end{array}$ \\
\hline
\end{tabular}




\begin{tabular}{|c|c|c|}
\hline $\begin{array}{l}13 \text { de } \\
\text { marzo } \\
\text { de } \\
2019\end{array}$ & $\begin{array}{l}\text { Manifestacion } \\
\text { es por } \\
\text { traslado de } \\
\text { comuneros } \\
\text { Tralcal }\end{array}$ & $\begin{array}{l}\text { Con una manifestación pacífica en las afueras de } \\
\text { las oficinas de la dirección de regional del } \\
\text { organismo, un grupo de familiares y cercanos a los } \\
\text { primos Luis Tralcal Quidel y José Tralcal Coche, } \\
\text { exigieron el traslado de los condenados hasta el } \\
\text { centro de cumplimiento penitenciario de la capital } \\
\text { de La Araucanía. }\end{array}$ \\
\hline $\begin{array}{l}09 \text { de } \\
\text { abril } \\
\text { de } \\
2019\end{array}$ & $\begin{array}{l}\text { Inicio } \\
\text { Consult } \\
\text { a Indígena }\end{array}$ & $\begin{array}{l}\text { Ministerio de Desarrollo Social inicia } \\
\text { procedimiento administrativo y convoca a proceso } \\
\text { de Consulta Indígena }\end{array}$ \\
\hline $\begin{array}{l}01 \text { de } \\
\text { mayo } \\
\text { de } \\
2019\end{array}$ & $\begin{array}{l}\text { Justicia } \\
\text { declara ilegal } \\
\text { detención de } \\
\text { dirigente } \\
\text { mapuche José } \\
\text { Queipul }\end{array}$ & $\begin{array}{l}\text { Juzgado de Garantía de Victoria declaró ilegal la } \\
\text { detención del dirigente mapuche José Queipul, que } \\
\text { la tarde de este martes fue detenido por } \\
\text { Carabineros luego de un operativo en el que } \\
\text { Queipul recibió un disparo en su muslo por parte } \\
\text { de los efectivos de Fuerzas Especiales. }\end{array}$ \\
\hline $\begin{array}{l}13 \text { de } \\
\text { mayo } \\
\text { de } \\
2019\end{array}$ & $\begin{array}{l}\text { Héctor Llaitul } \\
\text { presente } \\
\text { querella } \\
\text { contra fiscal } \\
\text { Moya y } \\
\text { Villalobos, cas } \\
\text { o Operación } \\
\text { Huracán }\end{array}$ & $\begin{array}{l}\text { El vocero de la Coordinadora Arauco Malleco } \\
\text { (CAM), Héctor Llaitul, presentó una querella en } \\
\text { contra del fiscal de Alta Complejidad de Rancagua, } \\
\text { Sergio Moya, por los presuntos vínculos que éste } \\
\text { tendría con la Operación Huracán, en la que el } \\
\text { comunero y otros seis mapuches fueron detenidos } \\
\text { tras un montaje realizado por Carabineros de La } \\
\text { Araucanía en septiembre de } 2018 \text {. }\end{array}$ \\
\hline $\begin{array}{l}26 \text { de } \\
\text { mayo } \\
\text { de } \\
2019\end{array}$ & $\begin{array}{l}\text { Vocero } \\
\text { Temucuicui } \\
\text { rechaza } \\
\text { Consulta } \\
\text { Indígena }\end{array}$ & $\begin{array}{l}\text { El werken de la comunidad autónoma de } \\
\text { Temucuicui, Jorge Huenchullan expresó su rechazo } \\
\text { a la Consulta Indígena y todas las acciones del } \\
\text { Gobierno que no tengan relación con la } \\
\text { recuperación de tierras, afirmando que los } \\
\text { terrenos desde donde han sido desalojados } \\
\text { volverán a ser ocupados. }\end{array}$ \\
\hline $\begin{array}{l}28 \text { de } \\
\text { mayo } \\
\text { de } \\
2019\end{array}$ & $\begin{array}{l}\text { Joven } \\
\text { mapuche } \\
\text { recibe un } \\
\text { disparo de } \\
\text { Carabineros } \\
\text { en medio de } \\
\text { recuperación } \\
\text { territorial }\end{array}$ & $\begin{array}{l}\text { Tras un operativo policial en la comunidad Antonio } \\
\text { Calbún, en Victoria, en La Araucanía, un joven } \\
\text { mapuche resultó baleado en la cabeza, luego que } \\
\text { Carabineros ingresara al predio. La comunidad se } \\
\text { encontraba en proceso de recuperación territorial } \\
\text { y, en medio de eso, el propietario del fundo habría } \\
\text { dado aviso a Carabineros. }\end{array}$ \\
\hline
\end{tabular}




\begin{tabular}{|c|c|c|}
\hline $\begin{array}{l}09 \text { de } \\
\text { junio } \\
\text { de } \\
2019\end{array}$ & $\begin{array}{l}\text { AMCAM llama } \\
\text { a suspender } \\
\text { Consulta } \\
\text { Indígena }\end{array}$ & $\begin{array}{l}\text { La Asociación de Municipios con Alcalde Mapuche } \\
\text { (AMCAM) emitió un comunicado pidiendo al } \\
\text { Gobierno que dé pie atrás y suspenda la realización } \\
\text { de la consulta. La organización manifestó su } \\
\text { "disconformidad al cómo se ha planteado el } \\
\text { proceso, por lo cual solicita suspender su } \\
\text { desarrollo para socializar y replantear los temas a } \\
\text { tratar mediante un acuerdo nacional". }\end{array}$ \\
\hline $\begin{array}{l}10 \text { de } \\
\text { junio } \\
\text { de } \\
2019\end{array}$ & $\begin{array}{l}\text { Comunidade } \\
\text { s de Tirúa } \\
\text { rechazan } \\
\text { Consulta } \\
\text { Indígena }\end{array}$ & $\begin{array}{l}\text { Un rechazo absoluto al proceso de Consulta } \\
\text { Indígena se produjo durante la jornada de este } \\
\text { sábado en Tirúa, luego que casi medio centenar de } \\
\text { representantes lafkenche se apostaran en las } \\
\text { afueras de la Escuela Municipal Eloísa González, } \\
\text { espacio que había sido dispuesto por la Comisión } \\
\text { Consultora del Ministerio de Desarrollo Social, } \\
\text { para llevar adelante esta instancia, la que ha sido } \\
\text { resistida en prácticamente todas las comunas } \\
\text { donde ha intentado imponerse. }\end{array}$ \\
\hline $\begin{array}{l}11 \text { de } \\
\text { junio } \\
\text { de } \\
2019\end{array}$ & $\begin{array}{l}\text { Chadwick } \\
\text { niega } \\
\text { responsabilid } \\
\text { ades en caso } \\
\text { Catrillanca }\end{array}$ & $\begin{array}{l}\text { El ministro del Interior, Andrés Chadwick, asistió a } \\
\text { la penúltima sesión de la comisión investigadora } \\
\text { sobre la actuación de su cartera, de Carabineros y } \\
\text { la PDI, en relación a la muerte del joven mapuche } \\
\text { Camilo Catrillanca; para responder las consultas de } \\
\text { los diputados. El ministro señaló que no esperaba } \\
\text { recibir un informe falso de Carabineros, situación } \\
\text { que calificó de inaceptable y condenable. Indicó } \\
\text { que el primer documento que se le hace llegar } \\
\text { (documento ejecutivo) es una versión que viene } \\
\text { firmada por dos funcionarios de Carabineros. }\end{array}$ \\
\hline $\begin{array}{l}21 \text { de } \\
\text { junio } \\
\text { de } \\
2019\end{array}$ & $\begin{array}{l}\text { INDH amplía } \\
\text { querella } \\
\text { contra dos } \\
\text { exgenerales } \\
\text { por caso } \\
\text { Catrillanca }\end{array}$ & $\begin{array}{l}\text { El Instituto Nacional de Derechos Humanos (INDH) } \\
\text { amplió la querella contra exgenerales de } \\
\text { Carabineros por el caso Catrillanca. La acción } \\
\text { judicial apunta a Christian Franzani y Mauro } \\
\text { Victoriano, como presuntos encubridores del } \\
\text { crimen contra el comunero mapuche. }\end{array}$ \\
\hline $\begin{array}{l}02 \text { de } \\
\text { julio } \\
\text { de } \\
2019\end{array}$ & $\begin{array}{l}\text { Comunidade } \\
\text { s de Collipulli } \\
\text { rechazan } \\
\text { Consulta } \\
\text { Indígena }\end{array}$ & $\begin{array}{l}\text { Comunidades mapuches de Collipulli rechazaron la } \\
\text { Consulta Indígena del Gobierno, al igual que en la } \\
\text { mayoría de comunas del país. El Ejecutivo informó } \\
\text { que buscarán una nueva fecha para realizar el } \\
\text { procedimiento }\end{array}$ \\
\hline
\end{tabular}




\begin{tabular}{|c|c|c|}
\hline $\begin{array}{l}05 \text { de } \\
\text { julio } \\
\text { de } \\
2019\end{array}$ & $\begin{array}{l}\text { Citan a } \\
\text { declarar a } \\
\text { fiscal Moya } \\
\text { por } \\
\text { ocultamiento } \\
\text { de pruebas en } \\
\text { caso } \\
\text { Operación } \\
\text { Huracán }\end{array}$ & $\begin{array}{l}\text { El fiscal de Rancagua Sergio Moya prestará } \\
\text { declaraciones ante el Tribunal de Garantía de } \\
\text { Temuco, tras ser involucrado por uno de los } \\
\text { imputados de solicitar el ocultamiento de pruebas } \\
\text { de la fallida operación de inteligencia de } \\
\text { Carabineros. }\end{array}$ \\
\hline $\begin{array}{l}19 \text { de } \\
\text { julio } \\
\text { de } \\
2019\end{array}$ & $\begin{array}{l}\text { Comunero } \\
\text { mapuche } \\
\text { muere } \\
\text { baleado por } \\
\text { dueño de } \\
\text { predio en } \\
\text { Tirúa }\end{array}$ & $\begin{array}{l}\text { El comunero mapuche identificado como Lemuel } \\
\text { Gamali Fernández Toledo (25) fue baleado por un } \\
\text { particular durante la madrugada. La información } \\
\text { preliminar que se maneja es que Lemuel Gamali } \\
\text { recibió un impacto de bala por parte del dueño de } \\
\text { un predio, en el sector de Tranaquepe, cuando } \\
\text { habría ingresado al fundo. }\end{array}$ \\
\hline $\begin{array}{l}23 \text { de } \\
\text { julio } \\
\text { de } \\
2019\end{array}$ & $\begin{array}{l}\text { Condenan a } \\
\text { oficial de } \\
\text { Carabineros } \\
\text { por homicidio } \\
\text { frustrado de } \\
\text { comuneros } \\
\text { mapuche en } \\
\text { Tirúa }\end{array}$ & $\begin{array}{l}\text { La Fiscalía indicó que los comuneros recibieron } \\
\text { impactos de bala después de un incidente ocurrido } \\
\text { en la madrugada del } 26 \text { de diciembre en el sector } \\
\text { de Tranaquepe. En medio de esta situación los } \\
\text { carabineros utilizaron pistolas calibre } 9 \text { milímetros } \\
\text { y efectuaron al menos } 10 \text { disparos a una camioneta } \\
\text { donde se trasladaban cuatro personas. }\end{array}$ \\
\hline $\begin{array}{l}24 \text { de } \\
\text { julio } \\
\text { de } \\
2019\end{array}$ & $\begin{array}{l}\text { Rebajan } \\
\text { medidas } \\
\text { cautelares a } \\
\text { general } \\
\text { Gonzalo Blu }\end{array}$ & $\begin{array}{l}\text { Hasta antes de este fallo, el ex jefe de Inteligencia } \\
\text { de Carabineros se encontraba en prisión } \\
\text { preventiva. Ahora, tras la revisión del tribunal, las } \\
\text { medidas cautelares fueron rebajas, quedando Blu } \\
\text { con arresto domiciliario total y prohibición de } \\
\text { comunicarse con otros imputados en la misma } \\
\text { causa. }\end{array}$ \\
\hline $\begin{array}{l}27 \text { de } \\
\text { julio } \\
\text { de } \\
2019\end{array}$ & $\begin{array}{l}\text { Hostigamient } \\
\text { o y violencia } \\
\text { en contra de } \\
\text { familia de } \\
\text { lonko Curamil }\end{array}$ & $\begin{array}{l}\text { El pasado sábado, personas desconocidas } \\
\text { ingresaron a la vivienda del lonko Alberto Curamil, } \\
\text { causando destrozos y daños a la casa, sumándose } \\
\text { lo anterior, al hostigamiento y amedrentamiento } \\
\text { continuo que ha sufrido la familia del dirigente } \\
\text { mapuche hace casi un año. }\end{array}$ \\
\hline
\end{tabular}




\begin{tabular}{|c|c|c|}
\hline $\begin{array}{l}29 \text { de } \\
\text { agosto } \\
\text { de } \\
2019\end{array}$ & $\begin{array}{l}\text { Querella por } \\
\text { homicidio } \\
\text { frustrado } \\
\text { contra } \\
\text { Carabineros } \\
\text { por } \\
\text { comuneros } \\
\text { heridos en } \\
\text { Ercilla }\end{array}$ & $\begin{array}{l}\text { Una querella en contra de Carabineros, por el } \\
\text { delito de homicidio frustrado, ingresó en el } \\
\text { Juzgado de Garantía de Collipulli, la defensa de dos } \\
\text { comuneros mapuches de Ercilla que resultaron } \\
\text { heridos con numerosos perdigones, disparados a } \\
\text { corta distancia. }\end{array}$ \\
\hline $\begin{array}{l}07 \text { de } \\
\text { septie } \\
\text { mbre } \\
\text { de } \\
2019\end{array}$ & $\begin{array}{l}\text { Hortaliceras } \\
\text { mapuche } \\
\text { acuden a } \\
\text { DD.HH. tras } \\
\text { reiterada } \\
\text { violencia en } \\
\text { Temuco }\end{array}$ & $\begin{array}{l}\text { Dos asociaciones indígenas que representan a } 52 \\
\text { mujeres productoras y emprendedoras, asistieron } \\
\text { a la Comisión de DD.HH. de la Cámara de } \\
\text { Diputados, a denunciar que son tratadas como } \\
\text { delincuentes, y a solicitar el respeto de su cultura y } \\
\text { el derecho al trabajo que tienen. }\end{array}$ \\
\hline $\begin{array}{l}14 \text { de } \\
\text { octubr } \\
\text { e de } \\
2019\end{array}$ & $\begin{array}{l}\text { Formalizan a } \\
\text { Carabinero } \\
\text { por disparo } \\
\text { en ojo a } \\
\text { estudiante } \\
\text { mapuche en } \\
\text { Padre Las } \\
\text { Casas }\end{array}$ & $\begin{array}{l}\text { Un suboficial mayor en retiro de Carabineros, fue } \\
\text { formalizado por cuasidelito de lesiones graves } \\
\text { gravísimas, tras utilizar una escopeta para disparar } \\
\text { gas lacrimógeno, impactando con uno de los } \\
\text { proyectiles en el rostro de una estudiante mapuche } \\
\text { en } 2017 \text {. }\end{array}$ \\
\hline $\begin{array}{l}18 \text { de } \\
\text { octubr } \\
\text { e de } \\
2019\end{array}$ & $\begin{array}{l}\text { Inicio } \\
\text { Estallid } \\
\text { o Social }\end{array}$ & $\begin{array}{l}\text { Con diversas protestas en Santiago, se da inicio al } \\
\text { ciclo de movilizaciones conocido como Estallido } \\
\text { Social }\end{array}$ \\
\hline $\begin{array}{l}29 \text { de } \\
\text { octubr } \\
\text { e de } \\
2019\end{array}$ & $\begin{array}{lr}\text { Derriban } & \\
\text { busto } & \text { de } \\
\text { Pedro } & \text { de } \\
\text { Valdivia } & \text { y } \\
\text { Diego } & \\
\text { Portales } & \text { en } \\
\text { Temuco } & \end{array}$ & $\begin{array}{l}\text { Durante las movilizaciones convocadas por } \\
\text { distintas comunidades mapuche en apoyo a las } \\
\text { diferentes protestas que se han registrado en el } \\
\text { país, dos estatuas han sido derribadas por grupos } \\
\text { de manifestantes en Temuco. }\end{array}$ \\
\hline
\end{tabular}




\begin{tabular}{|c|c|c|}
\hline $\begin{array}{l}02 \text { de } \\
\text { novie } \\
\text { mbre } \\
\text { de } \\
2019\end{array}$ & $\begin{array}{lr}\text { Derriban } & \\
\text { estatua } & \text { de } \\
\text { Valdivia } & \text { y } \\
\text { Mendoza } & \text { en } \\
\text { Cañete } & \end{array}$ & $\begin{array}{l}\text { Cerca de } 500 \text { comuneros mapuche llegaron al } \\
\text { sector a participar en una marcha convocada en la } \\
\text { zona. En este contexto, los bustos fueron } \\
\text { arrancados de sus bases, rayados y lanzados al } \\
\text { piso. }\end{array}$ \\
\hline $\begin{array}{l}14 \text { de } \\
\text { novie } \\
\text { mbre } \\
\text { de } \\
2019\end{array}$ & $\begin{array}{l}\text { Primer } \\
\text { aniversario } \\
\text { del asesinato } \\
\text { de Camilo } \\
\text { Catrillanca }\end{array}$ & $\begin{array}{l}\text { Primer aniversario del asesinato de Camilo } \\
\text { Catrillanca, perpetuado por funcionarios de } \\
\text { Carabineros y el Comando Jungla. }\end{array}$ \\
\hline $\begin{array}{l}14 \text { de } \\
\text { novie } \\
\text { mbre } \\
\text { de } \\
2019\end{array}$ & $\begin{array}{l}\text { Derriban } \\
\text { estatua de } \\
\text { Arturo Prat } \\
\text { en Temuco }\end{array}$ & $\begin{array}{l}\text { Derriban estatua de Arturo Prat en medio de } \\
\text { incidentes aislados en Temuco. A un año del } \\
\text { asesinato del comunero mapuche, Camilo } \\
\text { Catrillanca, unas tres mil personas llegaron al lugar } \\
\text { donde se encontraba el monumento de Arturo Prat } \\
\text { para derribarlo. }\end{array}$ \\
\hline $\begin{array}{l}26 \text { de } \\
\text { novie } \\
\text { mbre } \\
\text { de } \\
2019\end{array}$ & $\begin{array}{l}\text { Curamil no } \\
\text { ngresa a juicio } \\
\text { en protesta } \\
\text { por inclusión } \\
\text { de prueba, } \\
\text { represión en } \\
\text { cárcel e } \\
\text { impunidad en } \\
\text { caso } \\
\text { Catrillanca }\end{array}$ & $\begin{array}{l}\text { Esta mañana se suspendió el juicio por el robo en } \\
\text { la Caja de Compensación Los Héroes de Galvarino } \\
\text { por negativa de los cuatro acusados a ingresar al } \\
\text { juicio, reclamando la inclusión de evidencia que no } \\
\text { estaba originalmente en la carpeta investigativa, la } \\
\text { represión sufrida ayer en cárcel de Angol y la } \\
\text { impunidad en el caso de Camilo Catrillanca }\end{array}$ \\
\hline $\begin{array}{l}30 \text { de } \\
\text { novie } \\
\text { mbre } \\
\text { de } \\
2019\end{array}$ & $\begin{array}{l}\text { Confirman } \\
\text { prisión } \\
\text { preventiva de } \\
\text { ex GOPE } \\
\text { Carlos } \\
\text { Alarcón y } \\
\text { familia de } \\
\text { comunero } \\
\text { exige cadena } \\
\text { perpetua }\end{array}$ & $\begin{array}{l}\text { El Tribunal Oral en lo Penal de Angol ratificó la } \\
\text { prisión preventiva del ex-sargento del GOPE de } \\
\text { Carabineros, Carlos Alarcón. El otrora uniformado } \\
\text { es indicado como quien disparó y asesinó a Camilo } \\
\text { Catrillanca el } 14 \text { de noviembre del año } 2018 \text {. }\end{array}$ \\
\hline
\end{tabular}




\begin{tabular}{|c|c|c|}
\hline $\begin{array}{l}01 \text { de } \\
\text { diciem } \\
\text { bre de } \\
2019\end{array}$ & $\begin{array}{l}\text { Consejo de } \\
\text { Lonkos llama } \\
\text { a mapuche a } \\
\text { unir criterios } \\
\text { para } \\
\text { participar de } \\
\text { una nueva } \\
\text { Constitución }\end{array}$ & $\begin{array}{l}\text { El Consejo de Lonkos de La Araucanía llamó a } \\
\text { todas las organizaciones mapuche del país a unir } \\
\text { criterios para participar en la construcción de una } \\
\text { eventual nueva Constitución, exigiendo al } \\
\text { Congreso escaños reservados en la Convención } \\
\text { Constituyente. }\end{array}$ \\
\hline $\begin{array}{l}12 \text { de } \\
\text { diciem } \\
\text { bre de } \\
2019\end{array}$ & $\begin{array}{l}\text { Anuncio } \\
\text { nuevo } \\
\text { Gobierno } \\
\text { mapuche } \\
\text { tras reunión } \\
\text { en Cerro } \\
\text { Ñielol }\end{array}$ & $\begin{array}{l}\text { El próximo } 11 \text { y } 12 \text { de diciembre en el cerro Ñielol } \\
\text { de Temuco, el Consejo de Todas las Tierras } \\
\text { convocó a un proceso constituyente, para iniciar - } \\
\text { lo que denominan- un autogobierno mapuche. }\end{array}$ \\
\hline $\begin{array}{l}13 \text { de } \\
\text { diciem } \\
\text { bre de } \\
2019\end{array}$ & $\begin{array}{l}\text { Absuelven a } \\
\text { lonko Alberto } \\
\text { Curamil lue } \\
\text { go de } 16 \\
\text { meses de } \\
\text { prisión } \\
\text { preventiva }\end{array}$ & $\begin{array}{l}\text { El Nobel Verde fue liberado y absuelto de todos sus } \\
\text { cargos tras estar más de un año en prisión } \\
\text { preventiva en la cárcel de Temuco. }\end{array}$ \\
\hline $\begin{array}{l}16 \text { de } \\
\text { diciem } \\
\text { bre de } \\
2019\end{array}$ & $\begin{array}{l}\text { Comunidad } \\
\text { de Tirúa } \\
\text { decide que se } \\
\text { retiren } \\
\text { empresas } \\
\text { forestales } \\
\text { tras histórica } \\
\text { votación }\end{array}$ & $\begin{array}{l}\text { La consulta ciudadana realizada en Tirúa, se } \\
\text { destacó, entre otras cosas, por preguntar si la } \\
\text { comunidad deseaba que continuaran las } \\
\text { cuestionadas empresas forestales y el monocultivo } \\
\text { de árboles en su territorio. En } 22 \text { mesas de } \\
\text { votación que se dispusieron en la comuna para esta } \\
\text { Consulta Ciudadana 2019, las preferencias } \\
\text { estuvieron afavor de la expulsión del monocultivo } \\
\text { forestal. }\end{array}$ \\
\hline
\end{tabular}

